\title{
A Probe into the Key Parameter Monitor of V2G System on Electric Vehicle Based on Wireless Power Transmission Technology
}

\author{
Wangcheng Zhu*, Zhenchao Xie and Xinshu Wan \\ Electric Power Research Institute of Hainan Power Grid Co., Ltd., Haikou 570125, Hainan Province, China \\ ${ }^{*}$ Corresponding author
}

\begin{abstract}
As it is both significant and practical to study how the bidirectional wireless power transmission system can be applied to the monitor control of electric vehicle under V2G environment, this paper analyzes how the bidirectional wireless power transmission system works, based on which, probes into the phase difference $\theta$, which will influence the energy transmission direction, and ratio-voltage $\sigma$, which will influence transmission efficiency. It also promotes that coaxial installation of detection coil on secondary side and main power coil can monitor the 2 parameters in real time, and it also provides how to access the parameter. By simulation and experiments, it proved the feasibility of this method, providing a reference research approach on related studies.
\end{abstract}

Keywords-bidirectional wireless power transmission; V2G; parameter monitor

\section{INTRODUCTION}

In the traditional power supply and distribution system, power is mainly supplied in the one-way method, that is, terminal equipment consuming energy from beginning to end. As the electrical vehicle can store energy, the Vehicle to Grid technique (hereinafter known as V2G in short) has been given wide attention and research, which changes the traditional oneway power consuming idea. By controlling the power interface of the electric vehicle, the bidirectional interaction and exchange can be achieved between the vehicle itself and the grid. The surplus power can be returned to grid, being part of the energy which can be adjusted and distributed. In this way, the distribution flexibility, reliability, and power utilization can all be improved. Tracing back to the 1990s, some researchers have shown their great interest in the V2G technology. And as early as 1995, Amory Lovins, the chief scientist from the Rocky Mountain Institute (hereinafter short for RMI) has proposed the concept of V2G. Later, Prof. William Kempton from University of Delaware led his team and further promoted this technology [1-5].

Currently V2G technology is still wired, however, if the wireless transmission method can be adopted, the power utilization efficiency can be greatly improved. As the new energy has got higher penetration rate in grid, this technology will no doubt enhance the interactivity between electric vehicle and grid. In addition, as charging piles occupy too much land, the application of wireless power transmission will relieve the land use pressure. Meanwhile, the charging timing of electric vehicle can be less concentrated by rational planning and scheduling, thus to lessen the shock on the gird causing by charging and discharging of large scale. At the moment, the mathematical modeling and key technology of bidirectional power transmission are both under exploration stage, with some fruit coming out. And the "one-to-one" [6-8] as well as the "one-to-many" [9-11] topological research on bidirectional wireless power transmission technology have been relatively mature. How to control the energy flow direction through the phase difference in the transducer outlet voltage has been verified in an effective way, yet how to apply the wireless power transmission to the V2G system of electric vehicle still has an uphill battle to fight. As the existing technique mainly relies on additional detection and communication system to monitor the primary and secondary outlet voltage, this thesis will analyze the phase difference $\theta$, which will influence the energy transmission direction, and ratio-voltage $\sigma$, which will influence transmission efficiency, based on which, it promotes to coaxially install detection coil on secondary side and main power coil, thus to monitor and access the two parameters. By simulation and tests, it proved the feasibility of this method, providing a reference research approach on related studies.

\section{THEORETICAL MODELING ANALYSIS}

\section{A. Working Principle Analysis on Bidirectional Wireless Power Transmission System}

As shown in Figure I, this system can be divided into 2 parts: the primary side and the secondary side, which are a symmetric topology structure. Both the primary and secondary side span a DC source, an H-shape inverter composed of 4 MOSFETs and related controller, resonator and resonance compensation mechanism. By adjusting the MOSFET gate driver signal, the power bidirectional transmission under the topology structure can be achieved. When power is transferred from the primary side to the secondary side, which means, the primary side serving as "the source" while the secondary serving as "the charged", the primary side H-shape inverter will act as high-frequency inverter, and the secondary H-shape inverter will be the controlled rectifier, and vice versa. 


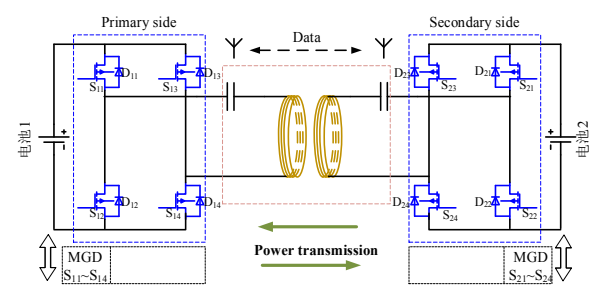

FIGURE I. THE BIDIRECTIONAL WIRELESS POWER TRANSMISSION SYSTEM STRUCTURE

As for the transitional wireless power transmission system, both the series LC fundamental type and the LCL composite type meet the resonant topology requirement, see Figure II about details of the two topology structures. To focus on the BD-WPT system energy transmission control technology, this paper only researches in the LCL composite resonant topology instead of analyzing on two different types of topology.

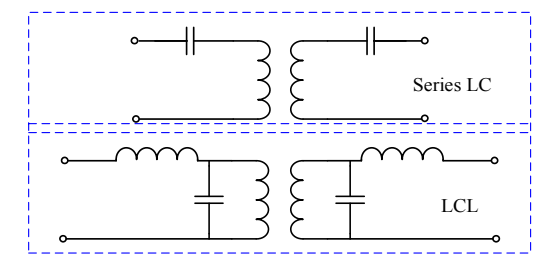

FIGURE II. THE LC AND LCL TOPOLOGY STRUCTURE DIAGRAM

The LCL bidirectional wireless power transmission system main circuit topology is as shown in the Figure III. As the BDWPT system boasts an equivalent topology structure, we can just take the transmission from primary side to secondary side as an example to analyze its working principle. In the primary side circuit, the dc voltage source $\mathrm{V}_{1}$ supplies power for BDWPT system. The LCL resonant circuit is composed of $\mathrm{L}_{\mathrm{m}}, \mathrm{C}_{1}$ and $\mathrm{L}_{\mathrm{p}}$, and the high frequency inverter is composed of MOSFET tube $S_{11} \sim S_{14}$ and anti-parallel diode $D_{11} \sim D_{14}$. In the secondary primary circuit, the controllable rectifier is composed of MOSFET tube $\mathrm{S}_{21} \sim \mathrm{S}_{24}$ and anti-parallel diode $\mathrm{D}_{21} \sim \mathrm{D}_{24}$., and the secondary side LCL resonant circuit is composed of $\mathrm{L}_{\mathrm{n}}, \mathrm{C}_{2}$ and $\mathrm{L}_{\mathrm{s}}$, with the battery $\mathrm{V}_{2}$ as the active load. $\mathrm{M}$ serves as the mutual inductance between the coupling coil $\mathrm{L}_{\mathrm{p}}$ and $\mathrm{L}_{\mathrm{s}}$.

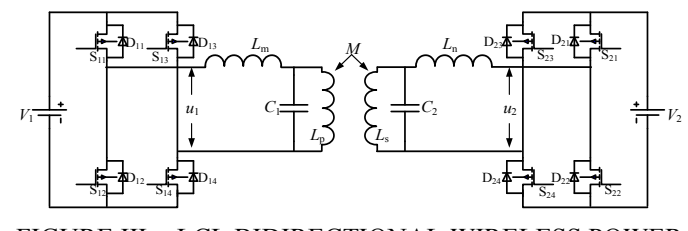

FIGURE III. LCL BIDIRECTIONAL WIRELESS POWER TRANSMISSION SYSTEM MAIN CIRCUIT TOPOLOGY

As for the LCL type BD-WPT system, if the H-shape trigger pulses in the two sides are controlled as shown in Figure IV, the power will be transmitted from the primary side to the secondary side. To be specific, when the control pulses of each MOS tube in the primary side are all $90^{\circ}$ ahead of its counterpart in the secondary side, $\mathrm{u}_{1}$, the outlet voltage of the $\mathrm{H}$-shape inverter in the primary side, will be $90^{\circ}$ ahead of $\mathrm{u}_{2}$, the counterpart in the secondary side. Take $u_{g s 11,14}$ opening at the moment of $t_{0} \sim t_{1}$ as an example, $L_{n}$, the current through the secondary series inductance generated by $\mathrm{u}_{1}$ positive semicircle, will be $90^{\circ}$ lagging behind $\mathrm{u}_{1}$, and meanwhile $\mathrm{u}_{2}$ will be $90^{\circ}$ lagging behind $\mathrm{u}_{1}$, too. At this moment, if $\mathrm{S}_{21}$ and $\mathrm{S}_{24}$ in the MOS tube of secondary side are opened simultaneously, the current through $L_{n}$ will have access to $V_{2}$, which means, supplying power to $\mathrm{V}_{2}$, that is, transmitting power from the primary side to secondary side, and vice versa, similarly.

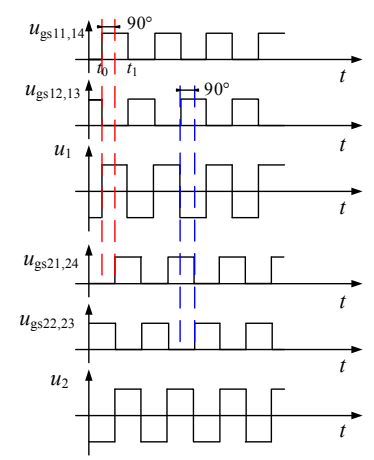

FIGURE IV. THE PULSE CONTROL WAVEFORM DIAGRAM AND OUTLET VOLTAGE WAVEFORM DIAGRAM WHEN POWER BEING TRANSMITTED FROM THE PRIMARY SIDE TO THE SECONDARY SIDE

The analysis above will lead to what is shown in the Figure $\mathrm{V}$, the LCL type BD-WPT equivalent circuit Diagram, of which, $L_{p}, L_{s}, R_{p}$, and $R_{s}$ represents the the coupling inductance and its Equivalent Series Resistance (hereinafter short for ESR) in the primary and secondary side correspondingly; $\mathrm{C}_{1}$ and $\mathrm{C}_{2}$ the resonant compensation capacitance of the primary and secondary side respectively; $L_{m}, L_{n}, R_{m}$, and $R_{n}$ the series filter inductance and ESR of two sides respectively. At the meanwhile, $L_{\mathrm{p}}=L_{\mathrm{m}}=L_{1}, L_{\mathrm{s}}=L_{\mathrm{n}}=L_{2}, R_{\mathrm{p}}=R_{\mathrm{m}}=R_{1}$, and $R_{\mathrm{s}}=R_{\mathrm{n}}=R_{2}$, to keep the circular frequency of the inverter switch being consistent with the resonator in the primary side and secondary side, that is, $\omega_{0}=1 / \operatorname{sqrt}\left(L_{1} C_{1}\right)=1 / \operatorname{sqrt}\left(L_{2} C_{2}\right)$. $\boldsymbol{U}_{\mathrm{p}}$ and $\boldsymbol{U}_{\mathrm{s}}$ represents the fundamental harmonic voltage phasor of the $\mathrm{H}$-shape inverter in the primary and secondary side respectively, assuming $\boldsymbol{U}_{\mathbf{p}}$ as the reference phasor, i.e. $\boldsymbol{U}_{\mathbf{p}}=U_{\mathrm{p}}<0^{\circ}$, the phase angle of $\boldsymbol{U}_{\mathrm{s}}$ as $\theta$, i.e. $\boldsymbol{U}_{\mathrm{s}}=U_{\mathrm{s}}<\theta, \boldsymbol{I}$ as the current phasor, $M$ as the mutual inductance between coil $L_{\mathrm{p}}$ and coil $L_{\mathrm{s}}, M=k \cdot \operatorname{sqrt}\left(L_{1} L_{2}\right)$, of which, $k$ being the coupling factor.

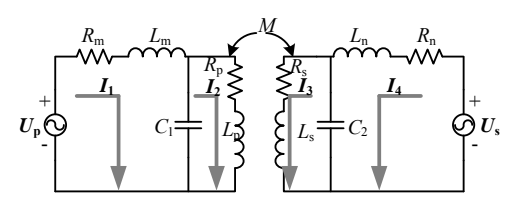

\section{FIGURE V. THE LCL TYPE BD-WPT EQUIVALENT CIRCUIT} DIAGRAM

According to the law of KCL, we obtain the voltage equation of LCL-type BD-WPT as:

$$
\left[\begin{array}{cccc}
R_{1} & j / \omega C_{1} & 0 & 0 \\
j / \omega C_{1} & R_{1} & j \omega M & 0 \\
0 & j \omega M & R_{2} & j / \omega C_{2} \\
0 & 0 & j / \omega C_{2} & R_{2}
\end{array}\right]\left[\begin{array}{c}
\boldsymbol{I}_{1} \\
\boldsymbol{I}_{2} \\
\boldsymbol{I}_{3} \\
\boldsymbol{I}_{4}
\end{array}\right]=\left[\begin{array}{c}
\boldsymbol{U}_{p} \\
0 \\
0 \\
\boldsymbol{U}_{s}
\end{array}\right] .
$$


Solving equation (1),

$$
\begin{aligned}
& \boldsymbol{I}_{1}=\left(a_{l c l} \boldsymbol{U}_{p}+j b_{l c l} \boldsymbol{U}_{s}\right) / \lambda_{0} \\
& \boldsymbol{I}_{4}=\left(c_{l c l} \boldsymbol{U}_{s}+j b_{l c l} \boldsymbol{U}_{p}\right) / \lambda_{0}
\end{aligned}
$$

In this connection, in LCL-type BD-WPT, the active and reactive power of the primary and secondary side can be expressed as:

$$
\begin{aligned}
& P_{p}^{l c l}=\frac{1}{2} \boldsymbol{R e}\left[\boldsymbol{U}_{p} \boldsymbol{I}_{1}^{*}\right]=\frac{1}{2} \frac{a_{l c l} U_{p}^{2}-b_{l c l} U_{p} U_{s} \sin \theta}{\lambda_{0}} \\
& P_{s}^{l c l}=\frac{1}{2} \boldsymbol{R e}\left[\boldsymbol{U}_{s} \boldsymbol{I}_{4}^{*}\right]=\frac{1}{2} \frac{c_{l c l} U_{s}^{2}+b_{l c l} U_{p} U_{s} \sin \theta}{\lambda_{0}} \\
& Q_{p}^{l c l}=\frac{1}{2} \mathbf{I m}\left[\boldsymbol{U}_{p} \boldsymbol{I}_{1}^{*}\right]=-\frac{1}{2} \frac{b_{l c l} U_{p} U_{s} \cos \theta}{\lambda_{0}} \\
& Q_{s}^{l c l}=\frac{1}{2} \mathbf{I m}\left[\boldsymbol{U}_{s} \boldsymbol{I}_{4}^{*}\right]=-\frac{1}{2} \frac{b_{l c l} U_{p} U_{s} \cos \theta}{\lambda_{0}}
\end{aligned}
$$

When $\theta=-90^{\circ}$, the power will transmit from the primary side to the secondary side, and we will obtain a positive efficiency as:

$$
\eta_{f o r}^{l c l}=\frac{\left|P_{s}^{l c l}\right|}{P_{p}^{l c l}}=\frac{b_{l c l} \sigma-c_{l c l} \sigma^{2}}{a_{l c l}+b_{l c l} \sigma}
$$

When $\theta=90^{\circ}$, the power will transmit from the secondary side to the primary side, and we will obtain a negative efficiency as:

$$
\eta_{i n v}^{l c l}=\frac{\left|P_{p}^{l c l}\right|}{P_{s}^{l c l}}=\frac{b_{l c l} \sigma-a_{l c l}}{c_{l c l} \sigma^{2}+b_{l c l} \sigma}
$$

\begin{tabular}{|c|c|}
\hline & LCL-type \\
\hline $\bar{\lambda} \lambda_{0}$ & $\omega_{0}{ }^{6} C_{1}^{2} C_{2}^{2} M^{2} R_{1} R_{2}+\omega_{0}^{4} C_{1}^{2} C_{2}^{2} R_{1}^{2} R_{2}^{2}+\omega_{0}^{2} C_{1}^{2} R_{1}^{2}+\omega_{0}^{2} C_{2}^{2} R_{2}^{2}+1$ \\
\hline$a$ & $\omega_{0}{ }^{6} C_{1}^{2} C_{2}^{2} M^{2} R_{2}+\omega_{0}^{4} C_{1}^{2} C_{2}^{2} R_{1} R_{2}^{2}+\omega_{0}^{2} C_{1}^{2} R_{1}$ \\
\hline$b$ & $\omega_{0}^{3} C_{1} C_{2} M$ \\
\hline$c$ & $\omega_{0}{ }^{6} C_{1}^{2} C_{2}^{2} M^{2} R_{1}+\omega_{0}^{4} C_{1}^{2} C_{2}^{2} R_{1}^{2} R_{2}+\omega_{0}^{2} C_{2}^{2} R_{2}$ \\
\hline
\end{tabular}

In the equation, $\sigma$ represents the ratio of $U_{\mathrm{p}}$ and $U_{\mathrm{s}}$, i.e. $\sigma=U_{\mathrm{s}} / U_{\mathrm{p}}$

and the parameter $a_{l c l}, b_{l c l}, c_{l c l}$ are as shown in the Table I.

TABLE I. BD-WPT TRANSMISSION PARAMETER TABLE OF THE LCL TOPOLOGY STRUCTURE

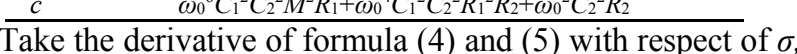
we can get the optimal ratio-voltage with LCL compensation structure bi-direction power transmission system under the forward and reverse transmission condition respectively as:

$$
\sigma_{f o r}^{o p t_{c l}}=\sqrt{\left(a_{l c l} / b_{l c l}\right)^{2}+a_{l c l} / c_{l c l}}-a_{l c l} / b_{l c l}
$$

$$
\sigma_{i n v}^{o p t_{l c}}=\sqrt{\left(a_{l c l} / b_{l c l}\right)^{2}+a_{l c l} / c_{l c l}}+a_{l c l} / b_{l c l}
$$

As analyzed above, the bidirectional wireless power transmission can be achieved by controlling the phase difference of primary and secondary side outlet voltage phasor.

As for BD-WPT system with the LCL compensation structure, the phase difference between the primary and secondary side of outlet voltage phasor is usually set to be $90^{\circ}$ or $90^{\circ}$ to achieve the forward or reverse direction transmission respectively. In the meantime, the system will boast different optimal ratio-voltage when working under forward or reverse transmission.

\section{B. Key Parameter Monitor of the Bidirectional Wireless Power Transmission System}

As for the LCL type BD-WPT system, $\theta$, the phase-angle difference of the H-shape inverter outlet voltage, and $\sigma$, the ratio between the voltage of two sides, are both key parameters to measure indicators like the system transmission power and efficiency. In this connection, these parameters need to be monitored during the whole transmission process for the sake of better control.

Figure VI shows the LCL type BD-WPT Equivalent Circuit Diagram after detective coil is introduced, and the parameters in the system is as what we have introduced in the section 2.1. In addition, Mpb1 and Mpb2 represent the mutual inductance between the detective coil and the primary and secondary coil.

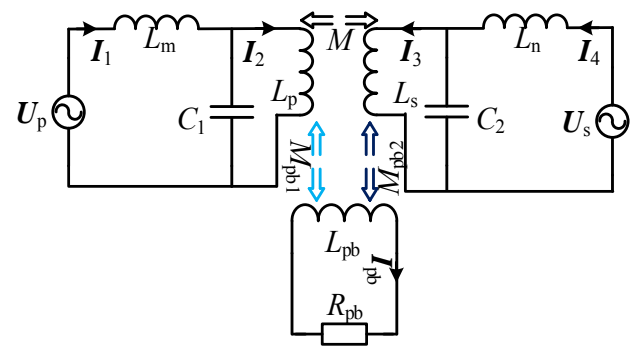

FIGURE VI. THE LCL TYPE BD-WPT EQUIVALENT CIRCUIT DIAGRAM WITH DETECTIVE COIL BEING INTRODUCED

The current equation in the circuit can be obtained based on Figure VI, as shown in Equation (8),

$$
\left\{\begin{array}{l}
\boldsymbol{I}_{1}=k_{1}\left(k_{1} \boldsymbol{U}_{p}+k_{2} \boldsymbol{U}_{s}\right) / Z_{p b}+j M \boldsymbol{U}_{s} /\left(\omega_{0} L_{1} L_{2}\right) \\
\boldsymbol{I}_{4}=k_{1}\left(k_{1} \boldsymbol{U}_{p}+k_{2} \boldsymbol{U}_{s}\right) / Z_{p b}+j M \boldsymbol{U}_{p} /\left(\omega_{0} L_{1} L_{2}\right) \\
\boldsymbol{I}_{p b}=\left(k_{1} \boldsymbol{U}_{p}+k_{2} \boldsymbol{U}_{s}\right) / Z_{p b}
\end{array}\right.
$$

of which, $k_{1}=\omega_{0}^{2} M_{\mathrm{pb} 1} C_{1}, k_{2}=\omega_{0}^{2} M_{\mathrm{pb} 2} C_{2}, Z_{\mathrm{pb}}=R_{\mathrm{pb}}+\mathrm{j} \omega_{0} L_{\mathrm{pb}}$. 
And the voltage on the detective resistance $R_{p b}$ can be obtained as shown in Equation (9).

$$
\boldsymbol{U}_{\mathbf{p b}}=-R_{p b} /\left|Z_{p b}\right| \angle-\alpha\left(k_{1} U_{p} \angle \theta+k_{2} U_{s} \angle 0\right)
$$

In Equation (9), $\alpha$ represents the impedance angle between the detective coil and angle, i.e. $\alpha=\arctan \left(\omega_{0} L_{\mathrm{pb}} / R_{\mathrm{pb}}\right)$. Considering $R_{\mathrm{pb}}, Z_{\mathrm{pb}}$ and $\alpha$ are given, we can define $\boldsymbol{B}=k_{1} U_{\mathbf{p}}<\theta+k_{2} U_{\mathrm{s}}<0$ as the proper phasor of $\boldsymbol{U}_{\mathbf{p b}}$, writing it as the form of "amplitude-phase angle", as shown in Equation (10),

$$
\boldsymbol{B}=B \angle \delta
$$

of which, amplitude $B$ and the phase angle $\delta$ shown in Equation (11)and(12).

$$
\begin{gathered}
B=\sqrt{\left(k_{1} U_{p} \cos (\theta)+k_{2} U_{s}\right)^{2}+\left(k_{1} U_{p} \sin (\theta)\right)^{2}} \\
\delta=\arctan \left[k_{1} U_{p} \sin (\theta) /\left(k_{1} U_{p} \cos (\theta)+k_{2} U_{s}\right)\right]
\end{gathered}
$$

As we have assumed to install the detective coil and the secondary coil coaxially, we'd like to further assume that $U_{\mathrm{s}}$, the outlet voltage in the secondary side inverter is given, in this way we can evolve the Equation (11) and (12) to (13) and (14), of which, $k_{3}=k_{1} / k_{2}$, and the key parameters will be monitored based on Equation (13) and (14).

$$
\begin{gathered}
B^{\prime}=B /\left(k_{2} U_{s}\right)=\sqrt{\left(k_{3} \sigma \cos (\theta)+1\right)^{2}+\left(k_{3} \sigma \sin (\theta)\right)^{2}} \\
\delta=\arctan \left[k_{3} \sigma \sin \theta /(k \sigma \cos \theta+1)\right]
\end{gathered}
$$

Figure VII shows the relations between $\delta$ and $\sigma$ as well as $\theta$, and Figure $(A)$ is their three-dimensional diagram. For the convenience of analysis, we have given the relation curve between $\delta$ and $\sigma$ under the typical $\theta$ value, as well as the relation curve between $\delta$ and $\theta$ under the typical $\sigma$ value, shown in Figure VII (B) and (C). From (B), we can see that, when $\theta$ is some determined value, $\delta$ and $\sigma$ keep a monotonic relation, that is, with the diminishing of the value $\sigma, \delta$ decreases too. And from $(\mathrm{C})$, we can see that no matter what value $\sigma$ is, there is always a $\theta$ that makes a maximum $\delta$, which magnifies with the increasing of $\sigma$, deviating more from the $90^{\circ}$ angle.

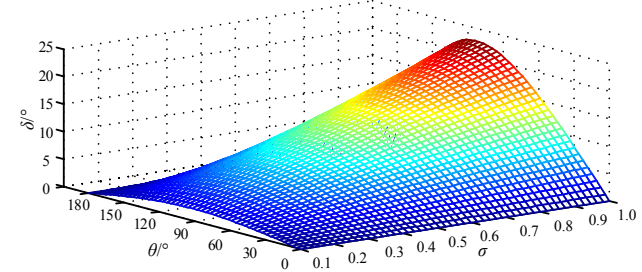

(A) Three-dimensional Diagram between $\delta, \sigma$, and $\theta$

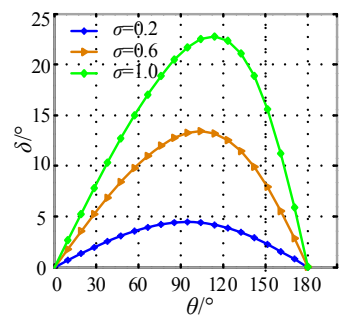

(B) Relationship between $\delta$ and $\sigma$ under the typical $\theta$ value

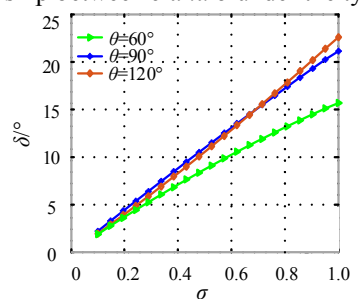

(C) Relationship between $\delta$ and $\theta$ under the typical $\sigma$ value

FIGURE VII. THREE-DIMENSIONAL DIAGRAM BETWEEN $\triangle$ AND $\Sigma$ AS WELL AS $\Theta$ AND THE RELATION CURVE UNDER TYPICAL VALUES

In addition, Figure VIII shows a set of typical relation curves between $B^{\prime}$ and $\sigma$ as well as $\theta$, and Figure $(A)$ is their three-dimensional diagram. For the convenience of analysis, we have given the relation curve between $B^{\prime}$ and $\sigma$ under the typical $\theta$ value, as well as the relation curve between $B^{\prime}$ and $\theta$ under the typical $\sigma$ value, shown in Figure VIII (B) and (C). From (B), we can see that, the relationship between $\sigma$ and $B$, will be affected and restricted by $\theta$. with some $\theta$ values, $B$ ' decreases with the diminishing of $\sigma$, while under some other $\theta$ values, $B$ ' increases with the diminishing of $\sigma$. And from $(C)$, we can see that $B^{\prime}$ decreases with the raising of $\theta$. Therefore, the value of $\theta$ and $\sigma$ can be uniquely indicated under a precise moment of B' and $\delta$ value. That is to say, the detected B' and $\delta$ value can be used to monitor the value of $\theta$ and $\sigma$ in real time, so as to keep the system efficiently working.

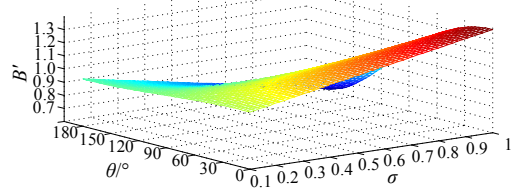

(A) Three-dimensional Diagram between $B$ ' and $\sigma$ as well as $\theta$

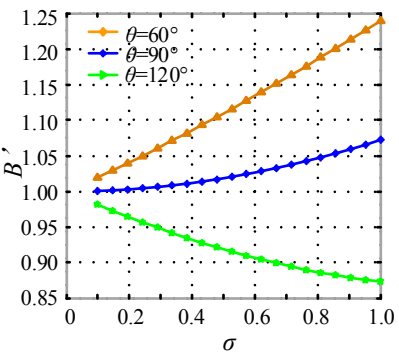

(B) the Relation Curve between $B$ ' and $\sigma$ under the typical $\theta$ value 


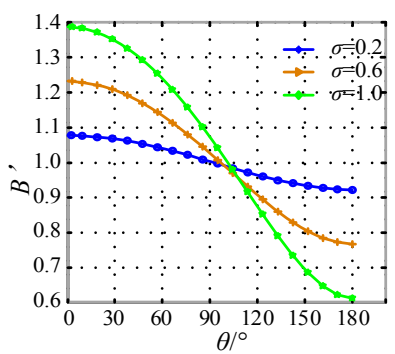

(C) the Relation Curve between $B^{\prime}$ and $\theta$ under the typical $\sigma$ value

FIGURE VIII. THREE-DIMENSIONAL DIAGRAM BETWEEN B' AND $\Sigma$ AS WELL AS $\Theta$ AND THE RELATION CURVE UNDER TYPICAL VALUES

\section{SIMULATION AND EXPERIMENT VERIFICATION}

Above we have analyzed the feasibility of how to use detective coil to monitor $\theta$ and $\sigma$ in theory, and what follows in the passage will be a related experiment, which will further prove and verify the accuracy of the designed results. We have established a simulation platform based on Matlab/Simulink, and the related hardware platform is designed as shown in Figure IX. See the system parameter allocation in TABLE II.

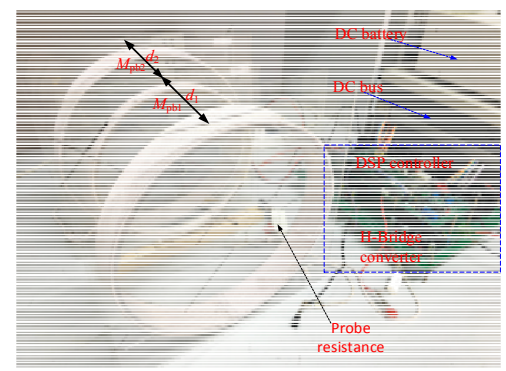

FIGURE IX. ARRANGEMENT PLAN OF THE DETECTIVE COIL

TABLE II.

2 SYSTEM PARAMETER ALLOCATION

\begin{tabular}{cc}
\hline Parameter & Values \\
\hline$L_{1}$ & $39 \mu \mathrm{H}$ \\
$L_{2}$ & $69 \mu \mathrm{H}$ \\
$L_{\mathrm{pb}}$ & $1.9 \mu \mathrm{H}$ \\
$R_{\mathrm{pb}}$ & $200 \Omega$ \\
$M_{12}$ & $4.8 \mu \mathrm{H}$ \\
$M_{\mathrm{pb} 1}$ & $0.65 \mu \mathrm{H}$ \\
$M_{\mathrm{pb} 2}$ & $0.94 \mu \mathrm{H}$ \\
$k_{3}$ & 0.3866 \\
\hline
\end{tabular}

A. Analysis of Phase Angle Monitoring Results of Primary Side Power Supply $U_{p}$

Let's assume the battery is being charged when the system functions well, that is to say, power is transmitted from the primary side to secondary side, i.e. the phase position of $\boldsymbol{U}_{\mathrm{p}}$ is $0 \sim 180^{\circ}$ ahead of $\boldsymbol{U}_{\mathrm{s}}$. In order to prove that the method proposed in this thesis is both correct and feasible to monitor $\theta$ in real time, $U_{\mathrm{p}}$ is being changed from time to time, so as to observe the $\boldsymbol{U}_{\mathrm{pb}}$ changes (the amplitude), and the result is shown in Figure $\mathrm{X}$. (A) shows the voltage amplitude changes in both sides of the detective resistance; (B) shows the voltage phase angle changes. When the system functions well under $\theta=90^{\circ}$, if $\mathrm{t}=16 \mathrm{~ms}, \theta$ will vary to be $72^{\circ}$, and both amplitude and phase angle will rise to be a new steady value after a fleeting $5 \mathrm{~ms}$ of oscillation. And similarly, if $\mathrm{t}=16 \mathrm{~ms}, \theta$ varies to be $108^{\circ}$, and oscillation will last about $7 \mathrm{~ms}$; when $\mathrm{t}=48 \mathrm{~ms}, \theta$ varies to be $126^{\circ}$; and $\mathrm{t}=64 \mathrm{~ms}, \theta$ varies to be $90^{\circ}$ again, both amplitude and phase angle can go after the change in a prompt manner. These data fully prove that the detective device can follow the $\theta$ changes in a timely and dynamic way.

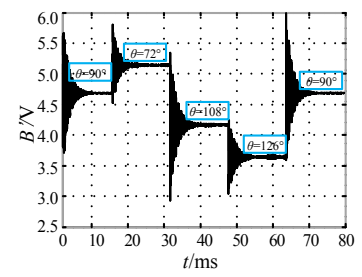

(A) The Dynamic Variation Diagram of $\delta$ with $\theta$

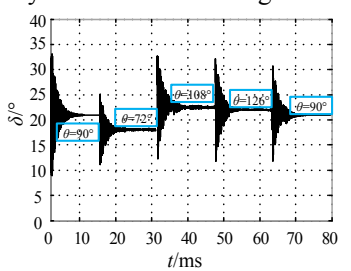

(B) The Dynamic Variation Diagram of $B$ ' with $\theta$

FIGURE $X$. THE DYNAMIC VARIATION DIAGRAM OF $\Delta$ AND B' WITH $\Theta$

Furthermore, when $\theta$ changes from $0^{\circ}$ to $180^{\circ}$ consecutively, the changing curve of the voltage amplitude and phase angel is as shown in Diagram 11. Results derived from simulation and experiments match the calculation basically. That means, even when $\theta$ varies in a larger range, the detective coil can do an accurate monitor.

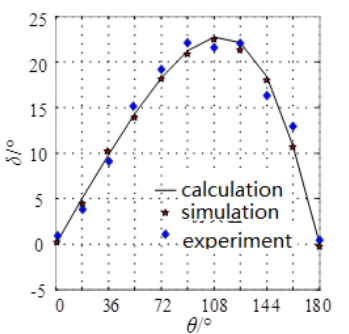

(A) the Changing Curve of $\delta$ with $\theta$

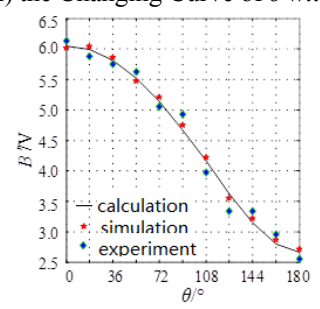

(B) the Changing Curve of $B$ ' with $\theta$

FIGURE XI. THE CHANGING CURVE OF $\triangle$ AND B' WITH $\Theta$ 


\section{B. Analysis of the Amplitude Monitoring Results of the Primary Side Power Supply $U_{p}$}

Similarly, Figure XII can prove that the method proposed in this thesis is both correct and feasible to monitor $\sigma$ in real time.(A) shows the dynamic change of voltage amplitude of the detective resistance; (B) shows the dynamic change on the voltage phase angle. When the system functions well under $\sigma=1$, if $\mathrm{t}=20 \mathrm{~ms}, \sigma$ will vary to be 0.75 , and both amplitude and phase angle will rise to be a new steady value after a fleeting moment of oscillation. And similarly, if $\mathrm{t}=40 \mathrm{~ms}, \sigma$ varies to be 0.25 , and $\mathrm{t}=60 \mathrm{~ms}, \sigma$ varies to be 0.5 ; and $\mathrm{t}=80 \mathrm{~ms}, \sigma$ varies to be 1. we can see from the dynamic diagram, both amplitude and phase angle can go after the change in a prompt manner. These data fully prove that the detective device can follow the $\theta$ changes in a timely and dynamic way.

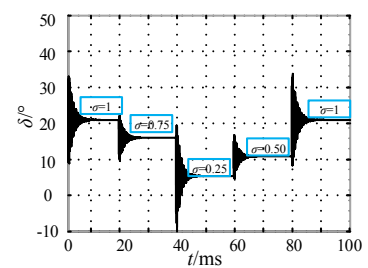

(A) The Dynamic Variation Diagram of $\delta$ with $\sigma$

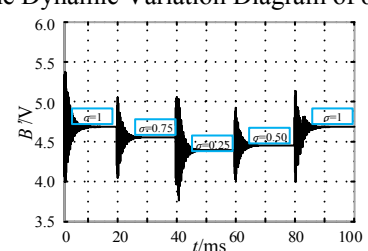

(B) The Dynamic Variation Diagram of $B$ ' with $\sigma$

\section{FIGURE XII. THE DYNAMIC VARIATION DIAGRAM OF $\triangle$ AND B' WITH $\Sigma$}

Furthermore, when $\sigma$ changes from 0.2 to 1 consecutively, the changing curve of the voltage amplitude and phase angel is as shown in Diagram 13. Results derived from simulation and experiments match the calculation basically. That means, even when $\sigma$ varies in a larger range, the detective coil can do an accurate monitor. And it provides enough evidence that $\sigma$ can be monitored by using the voltage amplitude and phase angel of detective resistance.

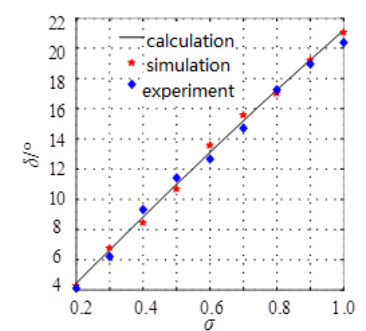

(A) the Changing Curve of $\delta$ with $\sigma$

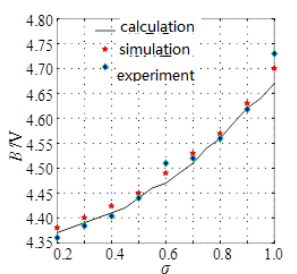

(B) the Changing Curve of $B$ ' with $\sigma$

FIGURE XIII. THE CHANGING CURVE OF $\triangle$ AND B' WITH $\Theta$

\section{CONCLUSION}

y analyzing the phase difference $\theta$, which will influence the energy transmission direction, and ratio-voltage $\sigma$, which will influence transmission efficiency, this paper verifies that, the bidirectional wireless power transmission can be achieved by controlling the phase difference of primary and secondary side outlet voltage phasor. In the meantime, the system will boast different optimal ratio-voltage when working under forward or reverse transmission. Based on the conclusion, it promotes that coaxial installation of detection coil on secondary side and main power coil can monitor the 2 parameters in real time. It not only provides how to access the parameter, but proves the feasibility by simulation and experiments, providing a reference research on how to apply the bidirectional power transmission system to V2G monitor control, on optimizing the control strategy of bidirectional wireless feeding system, and on the rational load allocation.

\section{ACKNOWLEDGEMENT}

This research is supported by China Southern Power Grid Corporation (Research and Application of Key Technologies of Intelligent Cloud Service in Hainan Power Grid).

\section{REFERENCES}

[1] LIU Xiaofei, ZHANG Qianfan, CUI Shuhai. Review of electric vehicle V2G technology. Transactions of China Electrotechnical Society, 2012, 27(2): 121-127.

[2] Kempton W, Tomić J. Vehicle-to-grid power fundamentals: Calculating capacity and net revenue. Journal of Power Sources,, 2005, 144(1): 268279.

[3] Kempton W, Tomić J. Vehicle-to-grid power implementation: From stabilizing the grid to supporting large-scale renewable energy. Journal of Power Sources, 2005, 144(1): 280-294.

[4] Madawala U K, Schweizer P, Haerri V V. "Living and mo-bility"novel multipurpose in-house grid interface with plug in hybrid BlueAngle// IEEE International Conference on Sustainable Energy Technologies. 2008: 531 - 536

[5] Iga Y, Omori H, Morizane T, et al. New IPT-wireless EV charger using single-ended quasi-resonant converter with power factor correction// International Conference on Renewable Energy Research and Applications. 2012: 1-6.

[6] Madawala U K, Thrimawithana D J. A Bidirectional Inductive Power Interface for Electric Vehicles in V2G Systems. IEEE Transactions on Industrial Electronics, 2011, 58(10): 4789-4796.

[7] Voglitsis D, Tsengenes G, Bauer P. Inductive power transfer system with improved characteristics// Transportation Electrification Conference and Expo. IEEE, 2014: 1-8.

[8] LI Yanling, SUN Yue, DAI Xin, et al. Modeling and control of an LCL bi-directional inductive power transfer system. Journal of Chongqing University: 2012, 35(10): 117-123. 
[9] Swain A K, Devarakonda S, Madawala U K. Modeling, Sensitivity Analysis, and Controller Synthesis of Multipickup Bidirectional Inductive Power Transfer Systems. IEEE Transactions on Industrial Informatics, 2014, 10(2): 1372-1380.

[10] Swain A K, Devarakonda S, Madawala U K. Modelling of multi-pick-up bi-directional Inductive Power Transfer systems// IEEE Third International Conference on Sustainable Energy Technologies. IEEE, 2012: 30-35.

[11] Thrimawithana D J, Madawala U K, Neath M. A P\&Q based synchronization technique for Bi-directional IPT pick-ups// IEEE Ninth International Conference on Power Electronics and Drive Systems. IEEE, 2011: 40-45 